\title{
GESTÃO PARTICIPATIVA COMO INSTRUMENTO DE INCLUSÃO DEMOCRÁTICA: $O$ CASO DOS COMITÊS GESTORES DE BAIRRO DO PROGRAMA NOVA BAIXADA
}

PARTICIPATIVE MANAGEMENT AS AN INSTRUMENT OF DEMOCRATIC INCLUSION: THE CASE OF THE NEIGHBORHOOD MANAGEMENT COMMITTEES OF THE NEW COASTAL PLAIN PROGRAM

\section{RESUMO}

Este artigo aborda a experiência dos Comitês Gestores de Bairro, canais de gestão participativa introduzidos na Baixada Fluminense pelo Governo Estadual do Rio de Janeiro para garantir a participação de moradores nas discussões referentes à implementação do Programa Nova Baixada. Para averiguar as potencialidades e os obstáculos encontrados por estes canais de participação nas decisões políticas locais e verificar se funcionaram efetivamente como instrumentos de inclusão democrática, utilizaram-se dados de uma pesquisa de campo realizada pela Universidade Estadual do Rio de Janeiro em 2005, que entrevistou moradores das áreas beneficiadas pelo Programa, membros dos Comitês e gestores do programa. Os resultados revelaram a hierarquização no processo decisório e a baixa participação da maioria da população nas deliberações, restringindo o funcionamento dos Comitês como instâncias participativas.

\section{Juliana Guaraná}

Assessora Econômica do Instituto Brasileiro de Siderurgia

juguarana@yahoo.com.br

\section{Sonia Fleury}

Professora da Escola Brasileira de Administração Pública e de Empresas, Fundação Getulio Vargas

sfleury@fgv.br

Recebido em 29.06.2006. Aprovado em 14.04.2008

Avaliado pelo sistema double blind review

Editor Científico: Organizadores do Fórum de Organizações Sociais

\begin{abstract}
This article deals with the experience of the Neighborhood Management Committees, participative management channels that were introduced in the Fluminense Coastal Plain area [close to Rio de Janeiro] by the Rio de Janeiro State Government, with the idea of guaranteeing that local residents participate in any discussions relative to the implementation of the New Coastal Plain Program. In order to check the potential and the obstacles encountered by these channels when it came to participating in local political decisions and to see if they worked effectively as instruments of democratic inclusion data was used that was taken from field research carried out by the State University of Rio de Janeiro in 2005 , which interviewed local residents from the areas that benefited from the program, members of committees and program managers. The results revealed the existence of the creation of a hierarchy in the decision-making process and reduced participation by the majority of the population in deliberations, which restricted the functioning of the committees as participative forums.
\end{abstract}

PALAVRAS-ChAVE Democracia, Participação Popular, Civismo, Programa Nova Baixada, Comitês Gestores de Bairro. KEYWORDS Democracy, popular participation, civism, New Coastal Plain Program, neighborhood management committees. 


\section{O REGIME DEMOCRÁTICO E SUAS LIMITAÇÕES}

Ao longo de sua evolução, a democracia apresentou várias formas, incorporou uma série de inovações e hoje se manifesta sob a forma do regime representativo, em que a população, através do sistema eleitoral, realiza a escolha de um representante ao qual delegará o poder de decisão política. De acordo com Hirst (1992), a democracia representativa possui capacidade limitada de desempenhar a tarefa que lhe é atribuída, uma vez que os eleitores apenas escolhem algumas das pessoas envolvidas na tomada de decisão governamental, mas não possuem o poder de executá-la diretamente. Ainda conforme o autor, os eleitores encontram-se sempre na dependência de um conjunto muito restrito de candidatos, e freqüentemente escolhem partidos e líderes partidários por identificação, estando, em geral, mal informados sobre as propostas políticas. $\mathrm{Na}$ verdade, decidem em relação a partidos e pessoas, e não a políticas ou decisões.

Observa-se ainda que a democracia representativa temse mostrado incapaz de atender os grupos marginalizados. A representação não tem garantido, pelo método da tomada de decisão por maioria, que interesses minoritários tenham expressão na agenda governamental com a mesma facilidade dos setores majoritários ou economicamente mais prósperos. Esse tipo de problema é mais grave em países onde existe maior diversidade étnica e entre os grupos que têm maior dificuldade para obter o reconhecimento de seus direitos.

Assim, a democracia moderna deixou de ser um poder delegado pelo povo, tendo se convertido em forma de poder que, na verdade, é exercido sobre o povo por políticos profissionais e funcionários públicos substituídos periodicamente pelo mecanismo da eleição. Portanto, embora a democracia representativa possua a virtude de permitir que alguns dos principais responsáveis pela tomada de decisão no Estado sejam trocados ou periodicamente ameaçados de troca, tal aspecto, conforme afirma Hirst (1992), não deve ser superestimado como forma de controle.

Tais fragilidades ampliam-se quando em contexto de subdesenvolvimento - econômico, político e cultural -, como ocorre, por exemplo, no caso dos países latino-americanos, e, dentre eles, o Brasil. Segundo Fleury (2004), nesses países a exclusão de grande parte da população do campo de decisão política ainda é predominante, não tendo havido avanços nos direitos civis e sociais como se esperava, o que culminou na formação de uma democracia marcada pela inexistência de mecanismos de garantia desse tipo de igualdade.
Assim, pode-se afirmar que, apesar de o processo eleitoral ser um componente fundamental para a democracia, ele não é suficiente para garantir que a população desempenhe um papel realmente decisório neste regime. A participação da população na vida política das nações necessita aperfeiçoar-se.

Fleury (2002) defende que atualmente a democracia requer a incorporação do conceito de cidadania, que Marshall (1967) define como composto por três tipos de direito: direitos civis, direitos políticos e direitos sociais. Fleury (2002) complementa a teoria de Marshall, afirmando ainda que os direitos coletivos e o direito de participação na gestão pública também deveriam fundamentar a construção de uma estrutura democrática. Para a autora, a combinação de democracia representativa com democracia deliberativa constituiria um novo formato capaz de revigorar os regimes democráticos da atualidade.

Nesse sentido, mecanismos complementares ao regime representativo começaram a ser introduzidos, promovendo a inserção de minorias no cenário político. Dentre esses mecanismos, destacam-se no presente trabalho os canais de participação popular.

A fim de verificar as potencialidades e os obstáculos que os canais de participação podem encontrar, analisa-se o caso dos Comitês Gestores de Bairro, instâncias criadas pelo Governo Estadual do Rio de Janeiro com o intuito de possibilitar a participação de moradores em uma região marcada por forte exclusão, não apenas socioeconômica, mas também política: a Baixada Fluminense. A partir dos dados de uma pesquisa de campo realizada pela UERJ em 2005, procura-se verificar se os Comitês Gestores funcionaram efetivamente como instrumentos de inclusão democrática, garantindo de fato a participação de moradores nas discussões referentes à implementação do Programa Nova Baixada (PNB). Esses dados foram extraídos da dissertação de mestrado "A Importância do Componente Cívico para o Funcionamento Efetivo de Canais Participativos como Instrumentos de Inclusão Democrática: um Estudo de Caso dos Comitês Gestores de Bairro do Programa Nova Baixada" (2006), defendida na Fundação Getúlio Vargas.

\section{A PARTICIPAÇÃO POPULAR E SUAS LIMITAÇÕES COMO MECANISMO COMPLEMENTAR NO PROCESSO DE AMPLIAÇÃO DA DEMOCRACIA}

De acordo com Bordenave (1994), a introdução de mecanismos de participação popular seria o caminho mais adequado para enfrentar os complexos problemas que afligem 
democracias de países em desenvolvimento, uma vez que contribuiria para a consolidação efetiva do regime democrático e possibilitaria, por meio de uma gestão baseada na institucionalização das relações entre Estado e sociedade, a intervenção direta da população na vida pública.

No Brasil, a idéia de participação foi ganhando importância no final da década de 1970, quando, devido à ditadura, os movimentos populares adquiriram caráter político e iniciaram a luta em busca da redemocratização. Nesse contexto, começaram a surgir novas formas de organização e ganharam peso os questionamentos quanto às formas de gestão centralizadas, aumentando a pressão sobre o governo federal. De acordo com Sader (1988), os movimentos populares desse período, com destaque para o movimento sindical paulista, determinaram o surgimento de novos sujeitos sociais e históricos que foram fundamentais para a reconstrução da democracia no país. Para Sader, a mobilização e a formação de novas lideranças ocorridas na época constituíram-se nos fatores de derrubada da ditadura.

Assim, a partir das eleições diretas estaduais em 1982, os próprios governos passaram a introduzir mecanismos de participação na gestão pública, cedendo a fortes pressões populares. Os programas dos prefeitos eleitos passaram a incluir projetos de descentralização administrativa, criando estruturas locais como as regiões administrativas e os distritos sanitários.

A intensa mobilização da sociedade civil, organizada em prol da luta pela democracia, culminou no estabelecimento de quatorze princípios participativos pela Constituição de 1988. A partir de então, os canais de participação realmente se consolidaram no país. Dentre os quatorze princípios estabelecidos, encontra-se o de participação da sociedade civil em deliberações sobre políticas públicas relacionadas a crianças e adolescentes, assistência social e saúde, através dos chamados conselhos setoriais. Esses conselhos foram criados no interior do Poder Executivo, contando com a participação da sociedade civil e com a presença de representantes de provedores de serviços privados - no caso, representantes dos sistemas nacionais de assistência social e saúde. O papel dos participantes nos conselhos setoriais seria deliberar, juntamente com o poder público, sobre políticas a serem adotadas, exercer controle direto e regular as ações do governo.

Dentre as diferentes áreas de políticas sociais nas quais atualmente existem conselhos, destacam-se as experiências dos Conselhos de Saúde e do Orçamento Participativo. Os Conselhos de Saúde representam o setor de políticas públicas participativas mais bem institucionalizado no Brasil, com presença em $98 \%$ dos municípios brasileiros (PNUD, 2004). Já o Orçamento Participativo, fórum de decisão no qual a população delibera sobre as prioridades de obras de algumas prefeituras municipais, foi introduzido primeiramente na cidade de Porto Alegre, em 1989, e constitui-se numa das experiências de gestão democrático-participativas que mais se expandiram nas grandes cidades brasileiras: no ano de 2004, já existiam 194 experiências de orçamento participativo no país (PNUD, 2004).

No entanto, apesar de a participação realmente ter-se consolidado como instrumento de ampliação da democracia no Brasil, há uma série de limites às tentativas governamentais de desenvolver essas experiências. Diversas condicionantes existentes nas relações sociais do país têm dificultado, ou até mesmo comprometido, a atuação desses canais.

Segundo Carvalho e outros $(1999$, p. 7$)$, "a realidade histórico-política da sociedade brasileira impossibilita, em muitos âmbitos, a participação democrática dos brasileiros como cidadãos". Assim, características como patrimonialismo, personalismo e clientelismo continuam tendo uma grande influência na atuação dos canais de participação da população. Estes autores afirmam ainda que, embora existam algumas experiências nas quais as práticas participativas e democratizantes tenham realmente sido ampliadas na sociedade brasileira, na maioria dos casos as características mencionadas têm impedido a participação cidadã (FARIA e MONTEIRO, 2004).

Faoro (1979) relaciona as características da política brasileira às raízes portuguesas, afirmando que a origem do subdesenvolvimento nacional residiria no fato de o Brasil ter sido governado, desde os primórdios, pelo chamado "estamento burocrata", que manipulava bens e distribuía cargos e favores em seu próprio benefício. Para o autor, "de D. João I a Getúlio Vargas, numa viagem de seis séculos, uma estrutura político social resistiu a todas as transformações fundamentais, aos desafios mais profundos, à travessia do oceano" (FAORO, 1979, p. 133). Percebe-se, com isso, que o patrimonialismo, forma de dominação política em que não se distingue publico e privado, seria legitimado no caráter tradicionalista da cultura nacional, que perdura desde o Brasil Colonial até a República.

Convergente ao pensamento de Faoro (1979), Nunes (1997) acredita que a articulação entre sociedade e instituições formais no Brasil baseia-se em quatro padrões inter-relacionados: clientelismo, corporativismo, insulamento burocrático e universalismo de procedimento. $\mathrm{O}$ clientelismo é destacado como o traço dominante dessa articulação entre sociedade e sistema político, fazendo parte de uma tradição secular brasileira. Em todos os 
momentos da história do país, representou um comportamento esperado e desejado por políticos e eleitores, uma vez que constitui o principal canal de comunicação entre sociedade e Estado e fornece aos estratos mais baixos da população voz para demandas específicas. Dessa forma, a característica marcante das instituições formais do Estado brasileiro é a de troca de favores; as relações políticas estão baseadas em contatos pessoais, amizades e relações hierárquicas.

Da mesma forma, conforme assevera Avritzer (2002), apesar de realmente ter havido democratização do Estado e da sociedade, observa-se no Brasil a permanência de relações hierárquicas e pouco democráticas no interior dos conselhos, evidenciando elementos da cultura pouco participativa vigente no Brasil. De acordo com o autor, ainda é bastante significativo o número de comunidades nas quais a própria diretoria das associações decide quais serão as prioridades, o que demonstra que os elementos hierárquicos mantêm sua influência nas formas de deliberação.

Observa-se freqüentemente que quem não se destaca acaba excluído da participação. A administração participativa tem reproduzido estruturas de privilégio, ao invés de promover a igualdade social. Segundo Carvalho (2000), ocorre então o chamado "substituísmo": os setores "mais qualificados" das entidades passam a ser os porta-vozes de todos os segmentos, o que desfigura a representatividade dos conselhos.

É bastante freqüente também a cooptação de lideranças sociais por autoridades, levando ao esvaziamento das instâncias participativas ou à transfiguração de suas funções originais. Para Schwartzman (1982), os sistemas de cooptação ocupam um lugar intermediário entre sistemas corporativos e política aberta de grupos de interesse, criando "estruturas de participação débeis, sem consistência interna e sem capacidade organizacional própria" (SCHWARTZMAN, 1982, p. 53).

Diante do exposto, seria necessário que, conjuntamente à criação de instrumentos de inclusão democrática, fossem introduzidos meios de difusão de valores cívicos, numa atuação conjunta entre Estado e sociedade civil para que os valores e costumes da população caminhassem em direção a padrões mais democráticos.

Para Kymlicka e Norman (1997), o desenvolvimento de virtudes cívicas seria de extrema importância para a consolidação da democracia. Tais virtudes poderiam ser desenvolvidas por meio de um sistema educacional que apurasse o senso crítico dos cidadãos e que possuísse uma perspectiva moral que enfatizasse o coletivo. Para os autores, a própria atividade participativa seria o meio pelo qual indivíduos se habituariam a cumprir os deveres da cidadania. Nessa mesma linha, Fleury (2002) destaca o papel do Estado como educador, em todo esse processo, ressaltando, entretanto, que a transmissão de valores cívicos não se constitui em atribuição apenas do governo, mas também de todos os envolvidos no processo de socialização, entre eles a família e os meios de comunicação. Para a autora, a existência de incentivos ao comportamento cívico, bem como de sanções ao comportamento chamado "cínico" (REIS, 2001), seria decisiva para o predomínio de uma ou de outra atitude nas sociedades.

\section{PROCEDIMENTOS METODOLÓGICOS}

Considerando-se o critério de classificação proposto por Vergara (2003), a presente pesquisa pode ser classifica$\mathrm{da}$, quanto aos fins, como estudo de caso, uma vez que fica circunscrita à análise dos canais participativos introduzidos na Baixada Fluminense no âmbito do Programa Nova Baixada - os Comitês Gestores de Bairro. Quanto aos meios, os dados utilizados foram coletados a partir de pesquisa bibliográfica em textos sobre democracia e participação; pesquisa documental, com material colhido na Secretaria Estadual de Integração Governamental (SEIG), nos Comitês Gestores de Bairro e na Universidade Estadual do Rio de Janeiro (UERJ); e pesquisa de campo realizada por uma equipe da UERJ, entre maio e agosto de 2005.

A pesquisa foi realizada, pois, passados alguns anos da implementação do Programa Nova Baixada; o órgão financiador do projeto, o Banco Interamericano de Desenvolvimento (BID), solicitou uma avaliação das relações comunitárias desenvolvidas na região, visando, sobretudo, ao aprimoramento dos Comitês. Objetivando também formular um modelo com diretrizes para futuras intervenções, foi desenvolvido pela UERJ um projeto de acompanhamento dos Comitês Gestores de Bairro criados pelo PNB.

$\mathrm{Na}$ pesquisa realizada pela UERJ, foram selecionados quatro dentre os nove bairros abrangidos pelo PNB, cada bairro em um município distinto. Essa seleção teve como critérios a representatividade dos bairros nos respectivos municípios atendidos e das diferentes fases nas quais estes bairros passaram a ser atendidos pelo Programa. Foram escolhidos, assim, dois bairros da fase 1 (nos quais as obras já tinham sido finalizadas) e dois bairros da fase 2 (nos quais as obras haviam sido iniciadas, paralisadas e estavam sendo retomadas), o que possibilitou uma análise dos Comitês em diferentes momentos de implementação das obras. 
A coleta de dados foi efetuada por meio de entrevistas com beneficiários do programa (136 moradores dos quatro bairros), 13 membros dos referidos Comitês Gestores e 13 gestores do Programa Nova Baixada, pertencentes ao governo estadual do Rio de Janeiro, totalizando 162 entrevistados. Os moradores entrevistados foram escolhidos nas ruas dos bairros e os membros dos Comitês entrevistados foram sorteados de uma listagem dos participantes de cada Comitê. Quanto aos gestores, decidiu-se por entrevistar todos os gestores da SEIG (Secretaria Estadual de Integração Governamental), departamento do governo do estado responsável pelo PNB, que tiveram participação direta no programa.

As entrevistas seguiram roteiro que continha contendo os principais pontos a serem explorados oralmente. Perguntou-se sobre a estrutura e o funcionamento dos Comitês Gestores, o seu relacionamento com a comunidade e com os governos municipal e estadual, e o posicionamento dos entrevistados a respeito da participação popular na região e da atuação dos Comitês como instrumentos de inclusão democrática.

Apesar do roteiro, as entrevistas foram realizadas de maneira informal, no local de trabalho ou na moradia do entrevistado e não foram gravadas, mas registradas por meio de um relatório elaborado pelo entrevistador. Os relatórios eram detalhados e procuravam reproduzir minuciosamente as declarações. Durante as entrevistas, o comportamento dos entrevistados foi, em geral, bastante receptivo.

\section{CONTEXTUALIZAÇÃO DA EXPERIÊNCIA PARTICIPATIVA NA BAIXADA FLUMINENSE: 0 PROGRAMA NOVA BAIXADA (PNB) E OS COMITÊS GESTORES DE BAIRRO}

A região do estado do Rio de Janeiro denominada Baixada Fluminense é composta pelos municípios de Belford Roxo, Duque de Caxias, Japeri, Magé, Nilópolis, Nova Iguaçu, Queimados, São João de Meriti e pelo recém-emancipado município de Mesquita. Parte integrante da região metropolitana do Rio de Janeiro, esses municípios abrigam uma população de aproximadamente 3,5 milhões de habitantes (PNUD, 2004); é uma das áreas mais densamente povoadas do estado e onde se concentra, proporcionalmente, o maior número de pessoas em condições de indigência. A infra-estrutura urbana pouco desenvolvida, com um número considerável de ruas sem pavimentação, esgoto sanitário, coleta de lixo ou iluminação pública, contribuiu para agravar a situação de miséria da região.
Com o intuito de prover soluções para esses problemas, o governo do estado do Rio de Janeiro propôs, em 1995, ao Banco Interamericano de Desenvolvimento (BID), a implantação do Programa Nova Baixada (PNB), que teria como principal objetivo a melhoria da qualidade de vida em bairros dos municípios de Belford Roxo, Duque de Caxias, São João de Meriti e Mesquita, a partir de ações integradas, nas áreas social e de infra-estrutura, visando à urbanização dos bairros e ao resgate da cidadania de seus moradores.

As obras do PNB estariam também associadas ao desenvolvimento de atividades de mobilização e conscientização da população beneficiada, através da promoção de discussões em torno de questões ambientais, sanitárias, de saúde, educação e de geração de trabalho e renda. Dessa forma, seria fundamental para o sucesso do programa o estímulo ao conhecimento tanto por meio da difusão das informações sobre as intervenções em cada um dos nove bairros quanto através de um processo educativo continuado.

Para atingir esses objetivos e cumprindo uma das précondições do Contrato de Financiamento com o BID, acordado em setembro de 1997, que exigia a participação popular no programa, o governo do estado do Rio de Janeiro implementou Comitês Gestores nos bairros beneficiários do PNB. Os Comitês Gestores teriam como objetivos principais acompanhar as políticas públicas, propor sugestões de atuação e estabelecer canais sistemáticos de comunicação com os poderes públicos.

Esses comitês seriam encarregados ainda de apontar as principais necessidades da região nas áreas de educação, saúde, lazer e urbanização, bem como de acompanhar as obras realizadas pelo programa, fiscalizando-as e absorvendo as informações com os gestores de forma a manter a comunidade sempre informada.

Ademais, os Comitês Gestores de Bairro deveriam estimular a conscientização dos direitos e deveres da população beneficiada, através de esclarecimentos sobre as conseqüências de ações individuais e coletivas na própria comunidade. Para isso, deveriam enfatizar o papel do indivíduo na sociedade e na preservação do seu espaço de moradia, fazendo com que a população-alvo identificasse tanto as origens de seus problemas, quanto as suas próprias responsabilidades na solução dos mesmos.

Para que os Comitês Gestores desempenhassem suas funções com eficácia, foi-lhes concedido o direito de monitorar a ação pública (governo estadual), estabelecendo-se, para isso, canais sistemáticos de encontro entre Estado e comunidade, para discussões em torno do modelo de gestão dos serviços e repasse de informações acerca do Projeto. 
Não deveria haver qualquer tipo de remuneração por parte do governo do estado, prefeituras e empresas prestadoras de serviço no âmbito dos Comitês, de forma a não descaracterizar seu caráter voluntário e participativo. Qualquer morador que desejasse deveria ter o direito de se tornar membro do Comitê Gestor do bairro de sua residência, participando das reuniões, que deveriam ser abertas à comunidade, e da tomada de decisão.

Os Comitês deveriam realizar reuniões com freqüência, devido ao acompanhamento que fariam das intervenções; esquemas de atendimento à população deveriam ser introduzidos, de forma a assegurar a função de democratização da informação e o incentivo à participação social no âmbito das atividades do projeto. Além disso, a estrutura de funcionamento dos comitês deveria ser horizontal, não havendo qualquer espécie de hierarquia, de forma a garantir a participação da comunidade como um todo de maneira igualitária e democrática nos processos deliberativos.

\section{ANÁLISE DOS RESULTADOS}

Nesta seção, apresentam-se conseqüências da participação popular nas decisões políticas locais e discutem-se fatores que podem limitar o desenvolvimento de práticas participativas promovidas por Comitês Gestores.

\section{Acesso ao Processo Decisório e Desenvolvimento de Consciência Política}

Os dados coletados pelos pesquisadores da UERJ evidenciam que houve realmente certa participação dos Comitês Gestores de Bairro no que diz respeito à escolha das obras e dos locais a serem atendidos: embora as obras realizadas pelo PNB tenham sido predefinidas, os Comitês tiveram voz nas escolhas junto ao governo, opinando, contribuindo com informações, pedindo a inclusão de ruas e identificando situações que não haviam sido previstas. Assim, muitas obras foram iniciadas em pontos priorizados pelas próprias comunidades e algumas reivindicações consideradas pertinentes deram origem a alterações no projeto inicial. Foi através da solicitação dos comitês, por exemplo, que muitas ruas originalmente não incluídas no projeto para realização de obras foram reformadas. Conforme afirmou um gestor, "sempre ouvíamos as sugestões da comunidade na implementação dos projetos e muitas acabaram até sendo postas em prática. Só não foi possível atender todas as reivindicações porque os pedidos eram muitos e nem sempre viáveis, por questões técnicas ou financeiras". Coube às comunidades a escolha da localização das creches, dos postos de saúde e da praça a serem construídos, e dos nomes dessas unidades.

Ainda de acordo com as entrevistas realizadas, a grande maioria dos membros dos Comitês Gestores entrevistados sentia-se bastante satisfeita com sua participação no PNB. Pode-se concluir que a participação nos Comitês contribuiu para proporcionar a seus membros maior interesse pelos acontecimentos do município e por assuntos de política em geral. Um entrevistado relatou que sua participação no Comitê impactou de tal forma em sua conscientização política que o levou a filiar-se a um partido político. Outro entrevistado também se disse bastante satisfeito com o Comitê, principalmente por este se constituir em um espaço democrático, que valoriza os moradores e lhes concede a oportunidade de falar e reivindicar.

Além disso, segundo outro gestor entrevistado, a partir dos Comitês, os moradores adquiriram mais conhecimento a respeito das técnicas empregadas em obras públicas, como drenagem e canalização, e maior intimidade com o desenrolar da ação pública, permitindo-lhes identificar com maior facilidade os erros e acertos do Programa.

\section{Aspectos Limitantes dos Comitês Gestores de Bairro}

Nos quatro Comitês analisados, percebeu-se a existência de um núcleo participativo - a chamada "Comissão Executiva" -, que apresentava uma posição de grande destaque em relação aos demais membros, tendo inclusive maior poder de atuação junto à Secretaria Estadual de Integração Governamental (SEIG). As Comissões Executivas dos Comitês eram eleitas por meio de assembléias entre os moradores; os mais votados eram os indivíduos que já possuíam certo destaque ou liderança nas comunidades. Dessa forma, presidentes das associações e líderes comunitários se firmavam como membros executivos do Comitê Gestor. Foi relatado ainda, nas entrevistas realizadas, que muitos Comitês eram comandados por líderes que, com o tempo, se transformaram em funcionários da SEIG.

Alguns Comitês, além de possuírem a Comissão Executiva, possuíam também uma Comissão Ética. Quando havia abandono ou afastamento de algum membro da Comissão Executiva, um membro da Comissão de Ética passava a ocupar o seu lugar, o que evidenciava a existência de hierarquia dentro dos Comitês, contrariando uma de suas principais diretrizes de funcionamento.

Embora a periodicidade das reuniões nos Comitês variasse bastante entre os bairros pesquisados, em todos foi observada falta de divulgação das reuniões; embora a amostra não permita extrapolação, a grande maioria dos entrevistados não possuía conhecimento sobre a reali- 
zação das mesmas. Cabe destacar ainda que, em alguns bairros, as reuniões eram realizadas muito esparsamente. Segundo relatos, no período de obras, as reuniões costumavam ser mais freqüentes, e mesmo os comitês menos atuantes chegavam a se reunir de três a quatro vezes por mês, o que demonstra não ter havido uma continuidade no caráter participativo dos comitês.

Foi relatado também que membros do Comitê não integrantes da "Comissão Executiva" possuíam fraco poder nas decisões e não dispunham de todas as informações sobre os acontecimentos, obras e até mesmo sobre o próprio funcionamento do Comitê e suas reuniões. Houve uma série de reuniões fechadas, das quais só os membros executivos eram autorizados a participar. Nem a comunidade, nem os demais membros do Comitê tinham conhecimento do que era discutido nessas reuniões fechadas e, conseqüentemente, acabavam acompanhando as questões por alto. Da mesma forma, não eram todos os membros do Comitê que participavam das reuniões junto à SEIG.

Um dos gestores entrevistados revelou que, além da reunião mensal com todos os Comitês e da reunião local em cada município, havia uma reunião que ocorria todas as segundas-feiras pela manhã, da qual participavam os gestores e apenas poucos membros dos Comitês, os chamados "representantes".

Um membro não executivo do Comitê declarou: "Passei a participar mesmo como membro do Comitê há um ano e meio, mais ou menos. Neste um ano e meio, participei apenas de duas reuniões do Comitê. Se eles realizaram outras reuniões, não fiquei sabendo. [...] Deveria haver uma maior divulgação das reuniões, talvez até utilizando meios de comunicação ou através de palestras informativas à comunidade."

Três membros executivos entrevistados justificaram esta situação alegando que, na verdade, os membros não executivos não eram "fixos", pois entravam nos comitês e saíam dele conforme seus interesses. Em várias entrevistas, foi relatado que muitos membros saem do Comitê quando atingem seus objetivos - geralmente relacionados à conclusão das obras na rua de sua moradia -, permanecendo somente aqueles com forte característica de liderança; por esse motivo, estes últimos teriam vantagens em relação aos demais membros quanto a informações e participação.

Pode-se perceber que os Comitês Gestores apresentavam forte hierarquização interna, com membros de primeira linha (membros da Comissão Executiva que participavam das reuniões na SEIG), membros de segunda linha (demais membros da Comissão Executiva), membros de terceira linha (demais membros do Comitê) e membros de quarta linha (moradores que freqüentavam algumas reuniões abertas, mas que não eram membros do Comitê, não tendo participado dele efetivamente). Havia, dessa forma, concentração do processo decisório pela Comissão Executiva, o que acabava por enfraquecer a participação dos outros membros do Comitê e da própria população.

De acordo com os membros dos comitês e com os gestores entrevistados, a participação dos moradores nas reuniões era pequena. Segundo um dos gestores, o ideal seria que os Comitês tivessem reuniões grandes, com pelo menos $20 \%$ da população. Mas, em média, 50 pessoas participavam das reuniões. Os entrevistados na pesquisa atribuíram esse fato à ausência de uma divulgação maciça das reuniões, ausência de divulgação dos objetivos dos Comitês e ao baixo grau de associativismo e inexperiência organizativa característicos da sociedade brasileira. Nas palavras de uma gestora entrevistada: "Há uma grave falha nos Comitês Gestores de Bairro, pois não há mecanismo estruturado de comunicação. Os Comitês não possuem nenhuma estratégia de divulgação e, conseqüentemente, somente uma parte bem reduzida dos beneficiários dos bairros contemplados pelo PNB possui conhecimento do que seja um Comitê Gestor de Bairro, sendo este conhecimento, na maioria das vezes, bem vago."

A declaração acima foi confirmada nas entrevistas com moradores locais. A Tabela 1 apresenta os quatro bairros pela codificação adotada na pesquisa de campo, visando a manter o caráter sigiloso da pesquisa. No bairro 1 , dos 30 moradores entrevistados, 26 nunca tinham ouvido falar do Comitê Gestor do PNB, embora as entrevistas tenham sido realizadas nas proximidades da associação de moradores e das duas creches construídas pelo Programa. Dos entrevistados que não possuíam conhecimento sobre a existência do Comitê Gestor, três trabalhavam numa creche do próprio PNB e um trabalhava no posto de saúde do programa. Dentre os quatro beneficiários que possuíam conhecimento sobre o Comitê Gestor, um era diretor de uma das creches e membro Executivo do próprio Comitê, e os outros três, apesar de terem ouvido falar dele, nunca haviam participado das reuniões, alegando falta de divulgação e descrédito na influência do Comitê no PNB, uma vez que as obras tenham sido interrompidas muitas vezes e muitas ruas continuaram totalmente esburacadas.

No bairro 2, dos 30 moradores entrevistados, 23 nunca tinham ouvido falar do Comitê Gestor do PNB, embora as entrevistas também tenham sido realizadas nas proximidades da associação de moradores e da creche construída pelo Programa. Dos sete moradores que possuíam 
conhecimento sobre o Comitê Gestor, apenas um já havia participado de reuniões, uma vez que seu pai era um dos membros executivos.

Das 36 entrevistas no bairro 3, apenas 9 tinham conhecimento sobre Comitê Gestor de Bairro. Os demais, ou seja, 27 moradores da região nunca tinham ouvido falar do Comitê Gestor de Bairro. Dos 9 beneficiários que possuíam certo conhecimento sobre o Comitê Gestor de Bairro, verificou-se que apenas um participava do Comitê como membro, sendo também funcionário da SEIG.

No bairro 4, dos 40 beneficiários entrevistados, 29 disseram não conhecer o Comitê Gestor de Bairro e apenas 11 afirmaram conhecê-lo. Dentre os entrevistados que possuíam algum conhecimento sobre o Comitê Gestor, 2 eram membros do mesmo, 5 não eram membros, mas já participavam das reuniões (destes, um, apesar de já ter participado, acreditava haver muito jogo político) e os outros 4 nunca tinham participado, alegando falta de interesse e divulgação.

Os moradores entrevistados na pesquisa de campo nos quatro bairros possuíam faixa etária variada e em sua grande maioria eram residentes locais de longa data. Conforme pode ser observado na Tabela 1, dos 136 moradores entrevistados nas ruas dos bairros, apenas 31 (23\%) já tinham ouvido falar do Comitê Gestor de Bairro, enquanto 105 (77\%) não possuíam conhecimento de sua existência.

Observou-se ainda na pesquisa realizada pela UERJ existirem motivações diversas para a participação comunitária na Baixada Fluminense. Determinados membros eram movidos por ideais assistencialistas, com o intuito de ajudar os mais necessitados; outros, por interesse em resolver os problemas do bairro, em prol da qualidade de vida da comunidade. Mas havia também pessoas que eram movidas pelo objetivo de obter vantagens eleitorais.

Outro ponto bastante polêmico refere-se à questão da remuneração. Embora a maioria dos entrevistados tenha afirmado que nunca havia sido remunerado pelo programa (excetuando-se os casos de realização do curso de capaci- tação, que incluía meio período de aulas e meio período de trabalho), tendo atuado apenas de forma voluntária, alguns entrevistados contradisseram essa informação, assegurando que muitos dos membros executivos eram remunerados pelo acompanhamento das obras. Outros membros relataram terem sido remunerados, afirmando ainda que a remuneração deveria ser sempre concedida pelo Estado. Tais relatos evidenciam o fato de os Comitês terem assumido um caráter distinto do inicialmente idealizado.

As entrevistas também revelaram que a participação dos moradores nas reuniões aumentava conforme a possibilidade de empregar-se. Era grande a demanda por empregos na creche e no posto de saúde, de forma que, em épocas de inauguração, por exemplo, a participação nas reuniões aumentava consideravelmente. Já em épocas em que a ação no bairro encontrava-se parada, a participação se reduzia, não só por não haver interesses pessoais envolvidos, mas também pelo desânimo causado com a demora no início das obras.

Segundo um membro executivo do Comitê, "a maioria das reuniões conta com a participação de cerca de 50 pessoas, mas, quando há algum boato maior sobre inaugurações e obras, a participação tende a aumentar. Principalmente em períodos de realização de obras, a participação dos moradores nas reuniões aumenta bastante. Mas também, quando as obras e ruas ficam prontas, os moradores passam a não freqüentar mais as discussões".

Embora a participação nas reuniões seja aberta, permitindo-se a todos falar e participar durante os debates, os moradores não-membros dos comitês só podiam participar das reuniões dos comitês quando convidados. Foi relatado, ainda, que, em muitas reuniões, mesmo havendo em média 50 pessoas, apenas seis ou sete se manifestavam e participavam realmente.

Para um gestor entrevistado, o forte teor político dos Comitês era também um fator que atrapalhava a participação dos moradores, uma vez que "a comunidade só é

\section{Tabela 1 - Conhecimento dos moradores entrevistados a respeito dos comitês gestores de bairro}

\begin{tabular}{|l|c|c|c|}
\hline \multicolumn{1}{|c|}{ BAIRROS } & NÃO CONHECEM & OUVIRAM FALAR NO COMITEE & TOTAL DE ENTREVISTADOS \\
\hline Bairro 1 & 26 & 4 & 30 \\
\hline Bairro 2 & 23 & 7 & 30 \\
\hline Bairro 3 & 27 & 9 & 36 \\
\hline Bairro 4 & 29 & 11 & 40 \\
\hline TOTAL & 105 & 31 & 136 \\
\hline
\end{tabular}

Fonte: Relatório para a Promoção do Desenvolvimento das Relações Comunitárias no Estado do Rio de Janeiro: UERJ, 2005. 
realmente convocada às reuniões quando é interessante para os membros dos Comitês".

Deve-se destacar ainda que os membros entrevistados que não faziam parte da Comissão Executiva nunca tinham passado por nenhum tipo de capacitação promovida pelo $\mathrm{PNB}$, ou por não disporem de tempo para isso ou por não terem recebido informação sobre os cursos, o que mais uma vez evidencia discrepância entre o conhecimento dos membros executivos e não executivos.

\section{CONSIDERAÇÕES FINAIS}

Os Comitês Gestores de Bairro do Programa Nova Baixada constituem uma experiência inovadora na administração pública da Baixada Fluminense, apresentando vários aspectos positivos. A aproximação entre Estado e sociedade foi o principal deles, uma vez que foi aberta a possibilidade para que moradores de uma das regiões mais carentes do Estado do Rio de Janeiro, tradicionalmente excluídos do processo decisório, estabelecessem alguma ligação com os gestores do Programa por meio de sua participação, efetivada nas reuniões do Governo Estadual com os membros dos Comitês, o que simboliza importante conquista na questão da participação popular. Assim, pode-se afirmar que os participantes dos Comitês passaram a ter acesso direto às autoridades e aos gestores, tendo voz nos processos de implantação, administração e execução das obras e outros benefícios propostos pelo PNB.

Além disso, conforme declarações de entrevistados, os Comitês Gestores de Bairro contribuíram para que seus participantes passassem a ter maior interesse por acontecimentos do município, desenvolvendo seus conhecimentos sobre política e associativismo. Os membros dos Comitês Gestores adquiriam ainda uma série de informações a respeito da administração pública e das técnicas empregadas nas obras.

Entretanto, apesar dos benefícios que os Comitês Gestores agregaram à participação na Baixada Fluminense, foram observadas circunstâncias que comprometeram sua atuação como instrumentos de inclusão democrática.

Devido à forte hierarquização observada na estrutura interna dos Comitês Gestores de Bairro, o funcionamento desses canais participativos sofreu enfraquecimento. Dessa forma, os Comitês desviaram-se do objetivo a que se propunham, isto é, possibilitar a participação de todos. Transformaram-se em espaços representativos, em vez de participativos, reeditando o modelo vigente de democracia aos quais pretendiam ser uma alternativa. Acabaram por reproduzir as estruturas de privilégio, em processo de "substituísmo" (CARVALHO, 2000), no qual os setores que se destacam por algum motivo passam a ser os porta-vozes de todos os segmentos, desfigurando o caráter participativo das instituições.

O baixo grau de associativismo e de experiências organizativas na sociedade brasileira - segundo Carvalho (2000), a sociedade brasileira organizada ainda não representa mais do que $15 \%$ de sua população - é outra característica que marca o funcionamento dos Comitês Gestores de Bairro do Programa Nova Baixada, evidenciando a dificuldade de criação de formas estáveis de gestão democrática no país.

Assim, pode-se concluir que a mera introdução de canais participativos não é capaz, por si, de garantir o pleno direito à participação, pressuposto fundamental da democracia. Conforme afirmam Kymlicka e Norman (1997), a introdução de técnicas educativas e o estímulo ao associativismo e à organização constituiriam elementos importantes na caminhada em direção a padrões democráticos mais elevados, pois incentivariam o afloramento de virtudes cívicas na população. As próprias diretrizes do PNB previam estímulos educativos e organizativos às comunidades, como a realização de palestras, seminários, reuniões, oficinas, encontros e eventos referenciados nas obras e ações do PNB, buscando sempre incentivar a população no acompanhamento das melhorias implementadas. Porém, conforme se verificou, não se conferiu a devida atenção a esse aspecto do Programa, tendo havido falhas graves nos mecanismos de comunicação e de disseminação de informações.

Assim, para que canais participativos como os Comitês Gestores de Bairro atinjam efetivamente seus objetivos como instrumentos de inclusão democrática, seria necessário que a sua introdução fosse acompanhada de um movimento mais amplo, de um esforço conjunto entre Estado e sociedade, no sentido de transformar aspectos estruturais que dificultam o processo de democratização.

Finalmente, mesmo com todos os problemas que os canais participativos vêm enfrentando no Brasil, devese reconhecer o mérito dessas experiências e estimular o seu prosseguimento. A caminhada em direção à efetivação da democracia é um processo longo e árduo, que demandará muito empenho, tanto por parte do Estado, quanto da sociedade. Conforme afirma Sen (1999, p. 4 , tradução nossa),

\footnotetext{
"a questão não é saber se um país está preparado para a democracia, mas partir da idéia que o país se prepara através da democracia".
} 


\section{JULIANA GUARANÁ · SONIA FLEURY}

\section{REFERÊNCIAS}

AVRITZER, L. Orçamento participativo: as experiências de Porto Alegre e Belo Horizonte. In: DAGNINO, E (Org) Sociedade civil e espaços públicos no Brasil. São Paulo: Paz e Terra, 2002.

BORDENAVE, J. E. D. O que é participação? São Paulo: Brasiliense, 1994.

CARVALHO, A. I. Conselhos de saúde, responsabilidade pública e cidadania: a reforma sanitária como reforma do Estado. In: Saúde e democracia: a luta do CEBES. São Paulo: Lemos Editorial, 1997.

CARVALHO, J; CASTRO, R; REGO, V; MASSOQUETTE, B. B. Conselhos municipais: sua contribuição para o desenvolvimento local. In: ENCONTRO NACIONAL DA ASSOCIAÇÃO DOS PROGRAMAS DE PÓSGRADUAÇÃO EM ADMINISTRAÇÃO, 23이 1999, Foz do Iguaçu. Anais [...] Foz do Iguaçu: ANPAD, 1999.

CARVALHO, M. do C; TEIXEIRA, A. C. (Org) Conselhos gestores de politicas públicas. São Paulo: Polis, 2000.

CASTEL, R. Las metamorfosis de la cuestión social: una crónica del salariado. Buenos Aires: Paidós, 1997.

D'ARC, H; SILVA, P. Participação social: instrumento de gestão pública? Elementos para um debate sobre gestão de cidades brasileiras. Quais as perspectivas nos anos 90? Revista de Administração Pública, n. 30, v. 2, p. 44-70, jan./abr. 1996.

ERNANDEZ, M; GUARANÁ, J; MONTEIRO, M. G. Relatório final: promoção do desenvolvimento das relações comunitárias no Estado do Rio de Janeiro. Rio de Janeiro: UERJ, 2005.

FAORO, R. Os donos do poder. Rio de Janeiro: Editora Globo, 1979.

FARIA, VM; MONTEIRO, M G. Os canais de participação popular na gestão social: um estudo de caso na política nacional de qualificação. Revista Alcance, v.11, n.3, p. 445-460, set./dez. 2004

FEDOZZI, L. O poder da aldeia: gênese e história do orçamento participativo de Porto Alegre. Porto Alegre: Tomo Editorial, 2000.

FLEURY, S. A questão democrática na saúde. In: Saúde e Democracia: a luta do CEBES. São Paulo: Lemos Editorial, 1997.

FLEURY, S. Politicas sociales e ciudadanía. BID, INDES, 1999.

FLEURY, S. A expansão da cidadania. In: CONGRESO INTERNACIONAL DELCLADSOBRE LAREFORMADELESTADOYDELAADMINISTRACIÓN PÚBLICA, $7^{\circ}$, 2002, Lisboa. Anais [...] Lisboa: CLAD, 2002.
FLEURY, S. Ciudadanías, exclusión y democracia. Nueva Sociedad (Venezuela), v. 193, p. 62-75, set./out. 2004.

HIRST, P. A democracia representativa e seus limites. Rio de Janeiro: Jorge Zahar, 1992.

KYMLICKA, W; NORMAN, W. El retorno del ciudadano: una revisón de la producción reciente en teoría de la ciudadanía. La Política, n. 3. Buenos Aires: Paidós, 1997.

MAIA, J. G. V. A importância do componente cívico para o funcionamento efetivo de canais participativos como instrumentos de inclusão democrática: um estudo de caso dos Comitês Gestores de Bairro do Programa Nova Baixada. 2006. 112 f. Dissertação (Mestrado em Administração Pública) - Escola Brasileira de Administração Pública e de Empresas, Fundação Getulio Vargas, Rio de Janeiro.

MARSHALL, T. H. Cidadania, classe social e status. Rio de Janeiro: Zahar, 1967

NUNES, E. A gramática política do Brasil: clientelismo e insulamento burocrático. Rio de Janeiro: ENAP/Jorge Zahar, 1997.

PNUD. Informe sobre el desarollo democrático en América Latina, 2004

PUTNAM, R. Comunidade e democracia: a experiência italiana. Rio de Janeiro: Fundação Getulio Vargas, 1996.

REIS, F. W; CASTRO, M. M. M. Democracia, civismo e cinismo: um estudo empírico sobre normas e racionalidade. Revista Brasileira de Ciências Sociais, São Paulo, n. 45, v. 16, p.25-46, fev. 2001.

SADER, E. Quando novos personagens entram em cena. Rio de. Janeiro: Paz e Terra, 1988.

SANTOS, B. de S. (Org) Democratizar a democracia: os caminhos da democracia participativa. Rio de Janeiro: Civilização Brasileira, 2002.

SCHWARTZMAN, S. Bases do autoritarismo brasileiro. Rio de Janeiro: Editora Campus, 1982

SEN, A. Democracy as an universal value. Journal of Democracy, v. 10, n 3, p.3-17, 1999

TOURAINE, A. O que é a democracia? Petrópolis: Vozes, 1996.

VERGARA, S. C. Projetos e relatórios de pesquisa em administração. 4. ed São Paulo: Atlas, 2003 